\title{
A wing pod-based millimeter wavelength airborne cloud radar
}

\author{
J. Vivekanandan, S. Ellis, P. Tsai, E. Loew, W.-C. Lee, J. Emmett, M. Dixon, C. Burghart, and S. Rauenbuehler \\ Earth Observing Laboratory, National Center for Atmospheric Research (NCAR), Boulder, CO, USA \\ Correspondence to: J. Vivekanandan (vivek@ucar.edu)
}

Received: 23 January 2015 - Published in Geosci. Instrum. Method. Data Syst. Discuss.: 14 April 2015

Revised: 3 August 2015 - Accepted: 4 August 2015 - Published: 17 August 2015

\begin{abstract}
This paper describes a novel, airborne pod-based millimeter $(\mathrm{mm})$ wavelength radar. Its frequency of operation is $94 \mathrm{GHz}$ ( $3 \mathrm{~mm}$ wavelength). The radar has been designed to fly on the NCAR Gulfstream V HIAPER aircraft; however, it could be deployed on other similarly equipped aircraft. The pod-based configuration occupies minimum cabin space and maximizes scan coverage. The radar system is capable of collecting observations in a staring mode between zenith and nadir or in a scanning mode. Standard pulse-pair estimates of moments and raw time series of backscattered signals are recorded. The radar system design and characteristics as well as techniques for calibrating reflectivity and correcting Doppler velocity for aircraft attitude and motion are described. The radar can alternatively be deployed in a ground-based configuration, housed in the $20 \mathrm{ft}$ shipping container it shares with the High Spectral Resolution Lidar (HSRL). The radar was tested both on the ground and in flight. Preliminary measurements of Doppler and polarization measurements were collected and examples are presented.
\end{abstract}

\section{Introduction}

One attractive feature of millimeter $(\mathrm{mm})$ wavelength radar systems is their ability to detect micron-sized particles that constitute liquid and ice clouds. Even though the upper limit of transmit power at millimeter wavelength band is more than $25 \mathrm{~dB}$ lower than at centimeter bands ( $\mathrm{S}, \mathrm{C}$ and $\mathrm{X}$ bands), the larger backscatter cross section of particle sizes smaller than the wavelength (Rayleigh scattering) significantly improves the detection limit (Lhermitte, 1987; Clothiaux et al., 1995). The radar cross section at $\mathrm{W}$ band is $40 \mathrm{~dB}$ larger than at $\mathrm{X}$ band in the Rayleigh scattering regime. Another advantage of $\mathrm{mm}$ wavelength radars for airborne deployments is that the radar antenna is much smaller in size than the $\mathrm{cm}$ wavelength antenna for a specified angular beam resolution and the overall radar size is more compact. Therefore it is easier to achieve finer beam resolution $<1^{\circ}$ and range resolution on the order of tens of meters. Lower sidelobes and larger signal-to-clutter ratio at $\mathrm{mm}$ wavelength band radars significantly enhance their detection capability, in particular close to the radar (Kropfli and Kelly, 1996). However, mm wavelength radar signals are more susceptible to attenuation. The amount of attenuation is proportional to the intensity of the precipitation and gaseous absorption (Ellis and Vivekanandan, 2010, 2011). As a result, they are not suitable for observing even moderate precipitation.

Due to the above-described advantages of compact size, higher spatial resolution, and enhanced sensitivity, scanning or vertically pointing ground-based $\mathrm{mm}$ wavelength radars are used to study stratocumulus (Valli et al., 1998; Kollias and Albrecht, 2000), fair-weather cumulus (Kollias et al., 2001, 2002, 2007; Kollias and Albrecht, 2000) and fog properties (Hamazu et al., 2003). Airborne mm wavelength radars have been used for atmospheric remote sensing since the early 1990s (Pazmany et al., 1994; Horie et al., 2000; Hanesiak et al., 2010; Wolde and Vali, 2001a, b). Airborne cloud radar systems such as the University of Wyoming King Air Cloud Radar (WCR) and the NASA ER-2 Cloud Radar System (CRS) can observe clouds in remote regions and over the oceans (Li et al., 2004; WCR, 2012).

The scientific requirements of $\mathrm{mm}$ wavelength radar are mainly driven by climate and cloud process studies. Millimeter wavelength radar with dual-Doppler and dualpolarization capability is highly desirable for the concurrent estimation of dynamical and microphysical properties of clouds and precipitation. A polarization Doppler radar with dual wavelength and dual beams is capable of retrieving microphysical properties and two-dimensional winds. 
In 2005, a survey of the cloud radar user community was conducted in order to assess needs and help guide the design of a mm wavelength radar on the National Science Foundation (NSF) Gulfstream V (GV) High-Performance Instrumented Airborne Platform for Environmental Research (HIAPER) aircraft (Laursen et al., 2006), named HIAPER Cloud Radar (HCR). Results of the survey indicated a common preference for narrow-beam W-band radar with polarimetric and single Doppler capabilities with $-40 \mathrm{dBZ}$ sensitivity at $1 \mathrm{~km}$ range for airborne remote sensing of clouds. Additional desired capabilities included a second wavelength and/or dual-Doppler winds. Modern radar technology offers various options: dual-beam, dual-polarization and dualwavelength. Even though a basic Doppler radar system with a sensitivity of $-30 \mathrm{dBZ}$ is capable of satisfying many common scientific needs, the above-mentioned additional options significantly extend the measurement capabilities and further reduce any uncertainty in radar-based retrievals of cloud properties (Brown et al., 1995). Since the primary hardware requirements of the proposed HCR were that it be deployable on an airborne platform, use minimal cabin space and maximize scan coverage, a pod-based configuration was adopted. However, the size of the wing pod limited the fore and aft scanning capability, making airborne dual-Doppler retrievals impossible.

In order to complement the existing capabilities in the NSF Lower Atmospheric Observing Facility, the final configuration of the HCR will have Doppler, polarimetric and dualwavelength capabilities with a beam scanning option. When the radar is not deployed on the airborne platform, it can be operated in a ground-based configuration. The HCR shares a single $20 \mathrm{ft}$ shipping container with the NCAR High Spectral Resolution Lidar (HSRL) for operations on the ground, providing collocated measurements. This provides the impetus for combined radar-lidar studies and retrievals of more accurate micro-physical parameters, namely, mean particle size and precipitation amount (Donovan and van Lammeren, 2001).

A phased approach is used to build the HCR. Phase A consists of a pod-mounted W-band Doppler radar with coand cross-polarization measurements, i.e., reflectivity $(Z)$ and linear depolarization ratio (LDR). Pulse compression and differential reflectivity $\left(Z_{\mathrm{DR}}\right)$ capability are planned for phase $\mathrm{B}$, and a second wavelength, solid state, matched beam $K_{\mathrm{a}}$-band radar system is planned for phase C. In order to include these extensions the phase A system is designed to accommodate the phase $\mathrm{B}$ and $\mathrm{C}$ requirements to the extent possible. Phase A of the radar was ground-tested and flighttested in spring 2013, fall 2013 and fall 2014.

The goal of this paper is a system description of phase A of HCR including specifications, hardware and performance characteristics with example measurements. To this end, Sect. 2 describes the design concept of a pod-based radar system. Detailed radar block diagram and subsystem descriptions are presented in Sect. 3. Technical specifications of the

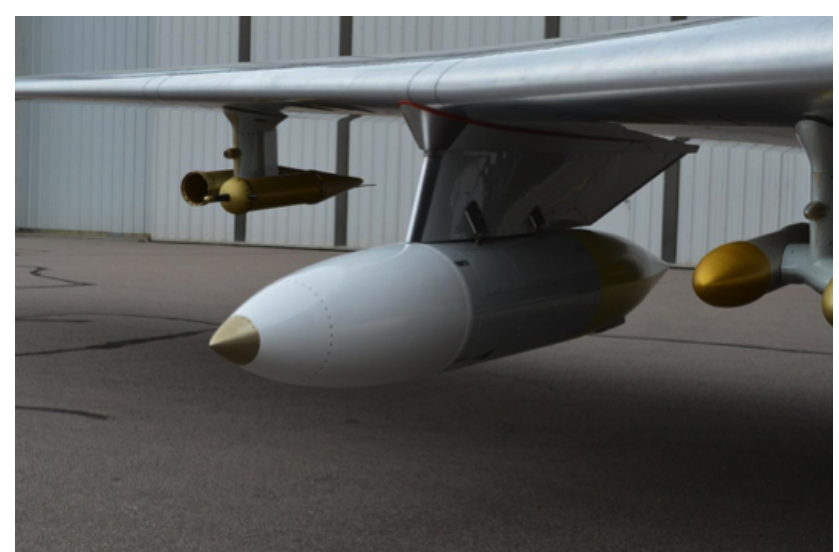

Figure 1. View of an NCAR pod mounted below the surface of the right wing.

HCR, expected sensitivity of the radar, spatial resolution of measurements, and measurement errors in velocity and reflectivity are described in Sect. 4. The calibration procedure for reflectivity and the correction of Doppler velocity for aircraft platform motion are shown in Sect. 5. Examples of HCR measurements are shown in Sect. 6. Section 7 presents a summary.

\section{Design concept}

The HCR is mounted in the underwing pod. The HIAPER underwing pod is attached to the mid-hardpoint of the right wing as depicted in Fig. 1. It is $20^{\prime \prime}$ (inches; $0.5 \mathrm{~m}$ ) in diameter and $160^{\prime \prime}(4.1 \mathrm{~m})$ in length. The total weight of the pod including instrumentation cannot exceed $800 \mathrm{lbs}(360 \mathrm{~kg})$. The HIAPER instruments located in wing pods must conform to the basic infrastructure of the wing pod. Power available onboard GV is limited and the number and type of connections in the wing pod are also pre-determined. Therefore the HIAPER instruments installed in the wing pod have to be designed taking into consideration the above-mentioned parameters. This necessitates that nearly the entire radar system be located within the pod; the radar control and data display/archive computer, however, are mounted in a $19^{\prime \prime}$ aircraft rack in the main cabin for communication and controls to the radar system. The overall weight of the pod, including the radar, is $514 \mathrm{lbs}(234 \mathrm{~kg})$.

A pod-based system on a high-altitude platform imposes engineering design challenges in terms of the radar's size, weight, and ability to handle pressure and temperature extremes. The National Center for Atmospheric Research Earth Observing Laboratory (NCAR EOL) performed the mechanical design and fabrication. They also generated the necessary drawings and documentation for FAA certification of the structure; FAA certification of all instrumentation is required for operation on the GV. 
Figure 2 shows the computer-aided design of the HCR system layout interior to the pod. The layout shows the placements of an inertial navigation system (C-MIGITS-III), a rotating reflector, a $12^{\prime \prime}$ lens antenna and a pressure vessel. The choice of the antenna is explained in Sect. 3.2. The pod is not environmentally controlled. In order to ensure a stable radar operation under conditions of temperature and pressure from sea level to $45000 \mathrm{ft}$ m.s.l. (mean sea level), all radar electronics including the high voltage transmitter are housed in the pressure vessel. This pressure vessel is $60^{\prime \prime}$ in length and $15^{\prime \prime}$ in diameter and is pressurized with dry nitrogen. To further mitigate potential arcing in the externally located waveguide and antenna feed, the antenna and associated waveguide are also pressurized through the pressure vessel. The $12^{\prime \prime}$ lens antenna illuminates a rotatable reflector plate that allows the coverage of a $220^{\circ}$ sector including zenith and nadir directions in the plane normal to the fuselage.

\section{Radar system description}

This section provides brief descriptions of the various radar sub-systems of the HCR including the transmitter and transceiver, antenna and radome, and the data system.

\subsection{Transmitter and transceiver}

A block diagram of the radar transceiver is shown in Fig. 3 . The HCR uses a conduction-cooled extended interaction klystron amplifier (EIKA) to amplify the signal for transmission. The EIKA is the similar to the one used in the CloudSat radar (Stephens et al., 2002). The EIKA, its modulator and the entire receiver electronics are housed in the pressure vessel. Since the modulator is rated for a maximum operating altitude $7000 \mathrm{ft}$ m.s.l., the pressure vessel must be maintained between 15 and 16 PSIA by a supplemental pressurization system. Both the EIKA and modulator are designed to operate at a $5 \%$ duty cycle. The $5 \%$ duty cycle will allow for pulse compression planned in phase B.

The HCR system transmits a single-frequency pulse with a programmable pulse width that can range from 256 to $1024 \mathrm{~ns}$ (38.4 to $153.6 \mathrm{~m}$ range resolution) at a $10 \mathrm{kHz}$ PRF (pulse repetition frequency). The receiver bandwidth is adjusted to match the bandwidth of the transmit pulse. A dual-channel receiver is used for measuring co- and crosspolarization signals. Each channel utilizes a two-stage superheterodyne receiver. The first stage intermediate frequency is $156.25 \mathrm{MHz}$ and the second stage is $1406.25 \mathrm{MHz}$. A $10 \mathrm{MHz}$ GPS STALO (stable local oscillator) is used as the system coherent source as well as the GPS location and time reference. All oscillators in the transceiver are phase locked to $125 \mathrm{MHz}$, which is ultimately referenced to the $10 \mathrm{MHz}$ GPS STALO.

At the front-end, a network of ferrite switches is used to alternate the transmit polarization and also achieve isolation

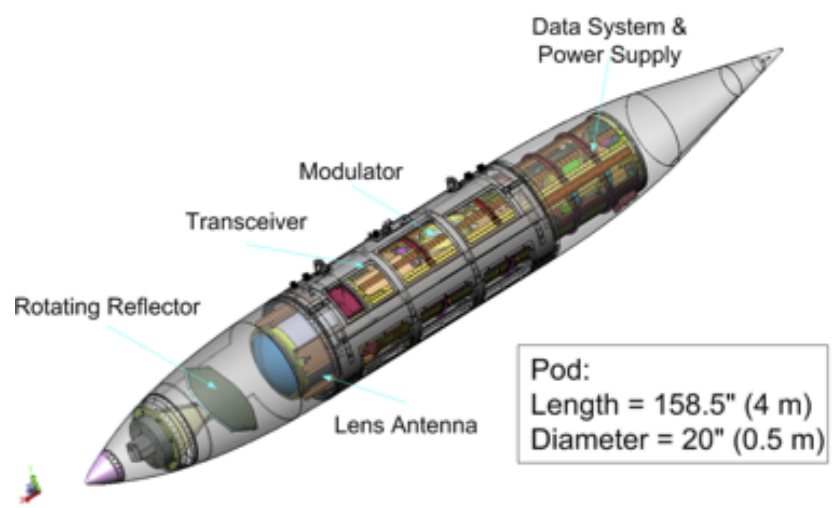

Figure 2. Side view of the $20^{\prime \prime}$ HIAPER wing pod showing the layout of the radar electronics. The front of the pod is on the lefthand side of the figure. The reflector plate is positioned such that the beam clears the leading edge of the wing when pointing toward zenith.

between transmit and receive paths. Three ferrite switches at the output of EIKA direct the transmit power between horizontal $(H)$ and vertical $(V)$ polarizations to provide alternating polarization capability. Three cascaded ferrite switches in front of the LNAs provide a minimum of $75 \mathrm{~dB}$ isolation to the receivers during the transmission.

A portion of the transmit signal is coupled through a $40 \mathrm{~dB}$ waveguide coupler, attenuated, and monitored by a crystal detector as shown in Fig. 3. A noise source is switched into the receiver's path periodically to monitor fluctuations in the receiver gain during operations (red path in Fig. 3). Due to the space limitation inside the pressure vessel, the noise source cannot be switched into both channels to monitor both receiver gains.

The phase B system will use pulse compression to increase the sensitivity of the system. To achieve low rangetime sidelobes with a pulse compression system, the spectrum of the transmitted pulse is shaped. All of the receiver components for the phase A system are designed for a greater than $20 \mathrm{MHz}$ passband to accommodate a pulse compression scheme. The sensitivity of the system is optimized to the pulse length used by digitally filtering the received signal to the desired signal bandwidth after digitization.

\subsection{Antenna and radome}

The dimensions of the pod limited the performance and capabilities of the HCR in two ways. First, the antenna aperture of the HCR is restricted to $12^{\prime \prime}$. This aperture constraint is necessary to avoid beam blockage by the pod's internal support structure as well as to enable zenith viewing through the use of a rotating reflector. This limits both the sensitivity and spatial resolution, as the gain of an antenna is directly proportional to its aperture, while its beamwidth is inversely proportional to its aperture. 


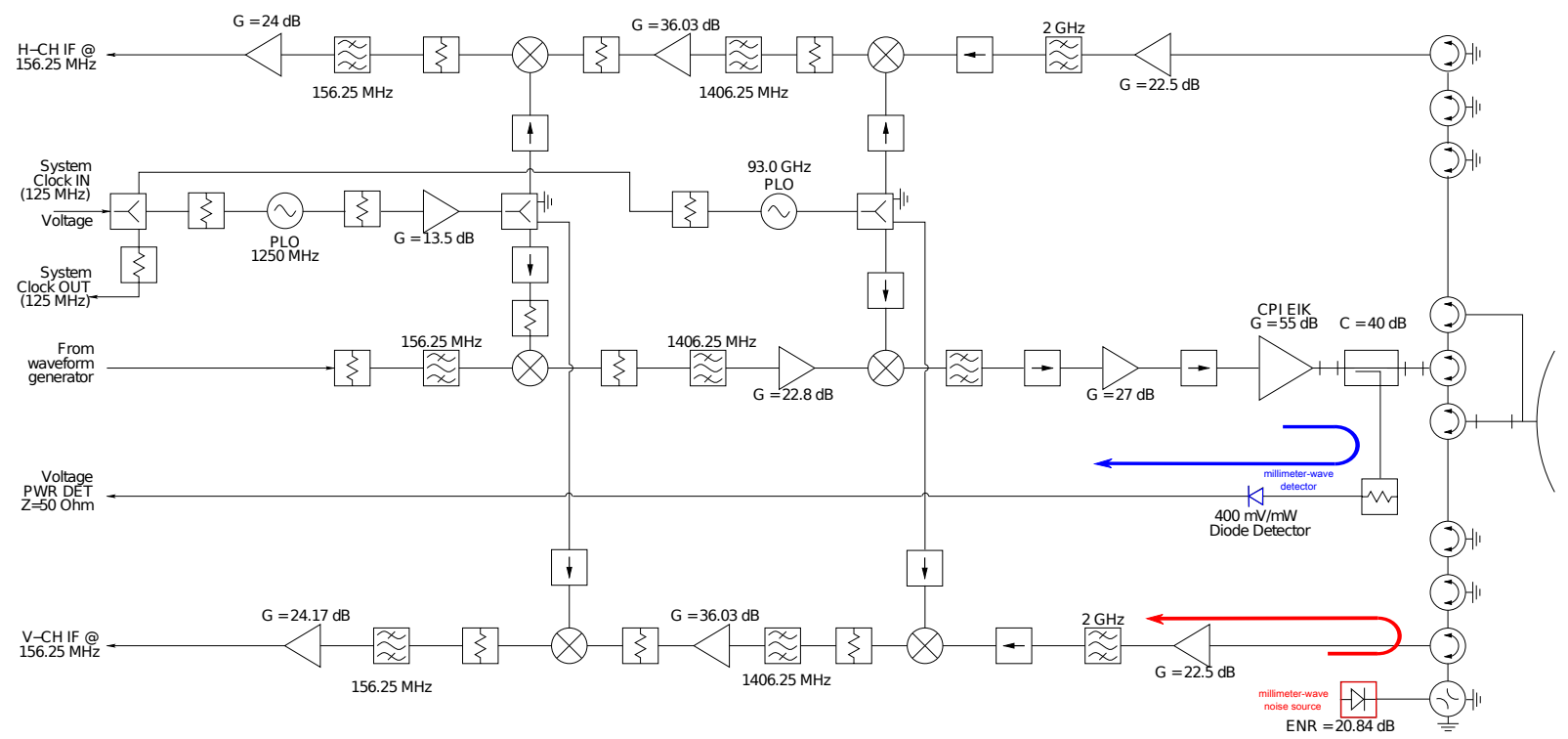

Figure 3. Block diagram of polarimetric HCR transceiver. The blue arrow couples the transmit signal for monitoring the transmitted power. The red arrow shows the signal path for monitoring receiver gain using a known noise source.

Part of the pod's nose cone is constructed with millimeter wavelength radome material. The design of this nose cone radome satisfies the following key requirements: structural robustness for aviation requirements, low loss at $\mathrm{W}$ and $K_{\mathrm{a}}$ bands, and electrical conductivity for preventing damages due to lightning strikes. One-way loss through the radome is expected to be $\sim 0.3 \mathrm{~dB}$ for $\mathrm{W}$ band and $\sim 0.2 \mathrm{~dB}$ for $K_{\mathrm{a}}$ band. The radome will also distort the relative phases of the incident wavefront due to its curvature.

The relative merits of two types of suitable antenna were considered in designing the HCR: (a) a parabolic reflector, including prime focus, Cassegrain and offset Gregorian, and (b) lens antennas. Planar arrays and their variants were not considered due to their lack of fast switching polarization capability. Lens antennas at millimeter wavelength frequencies give superior performance in terms of peak sidelobe level and cross-pol isolation over all parabolic types, with the possible exception of offset Gregorian. However, the complexity and required alignment precision of offset Gregorian antennas makes them less attractive in a pod based application where vibration and wide temperature variations exist. Although lens antennas are generally heavier and have larger focal length to diameter ratios than parabolic antennas, there is sufficient space and weight handling capability in the pod to accommodate the lens antenna. The co- and cross-pol antenna patterns are shown in Fig. 4. The first sidelobe is $\sim-20 \mathrm{~dB}$ and cross polarization lower than $38 \mathrm{~dB}$ at the bore sight.

A $45^{\circ}$ slanted rotating reflector plate in front of the antenna is used to steer the beam to meet angular coverage requirements. The reflector plate is constructed of aircraft grade aluminum, machined to a flatness of $0.005^{\prime \prime}(0.000127 \mathrm{~m})$ root

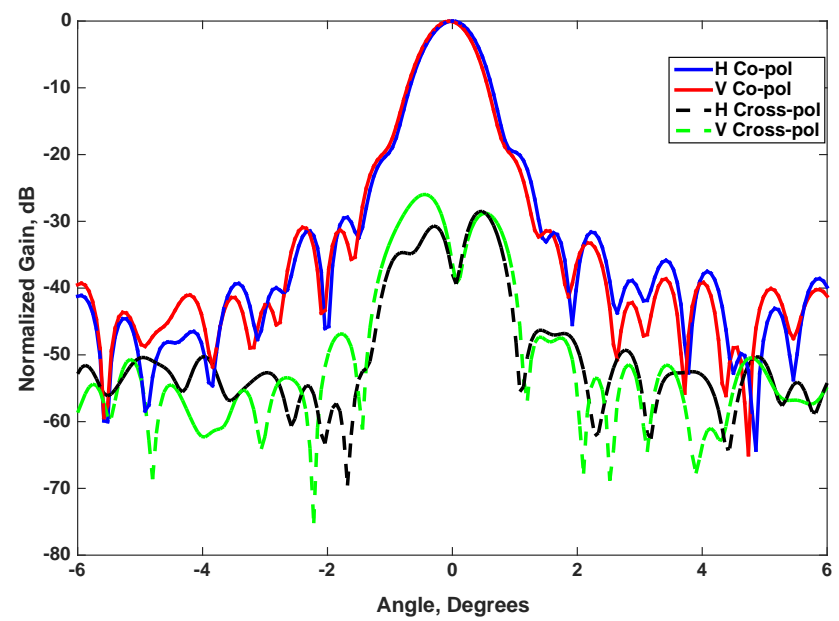

Figure 4. E-plane co- and cross-pol radiation patterns of HCR's lens antenna.

mean square (rms). The small rms value helps to maintain polarization purity of transmit and receive signals. Precise positioning of the plate relative to the antenna is required to avoid beam distortion and spillover. A brushless DC motor coupled with an optical shaft encoder is used to rotate the plate. A similar but smaller motor is used to adjust the tilt of the reflector. The motors are programed to rotate from $-10^{\circ}$ from zenith (toward the fuselage) to $210^{\circ}$ ( $30^{\circ}$ from nadir) perpendicular to along-track direction and from -6 to $+6^{\circ}$ in the tilt axis. The tilt axis adjustment compensates for the aircraft pitch. Both rotation and tilt are controlled in real time to compensate for platform motion to minimize the bias of aircraft motion into the velocities. A CMIGITS-III inertial 
Table 1. HCR specifications.

\begin{tabular}{ll}
\hline Parameter & Specification \\
\hline Transmit frequency & $94.4 \mathrm{GHz}, \mathrm{W}$-band \\
Antenna diameter & $0.30 \mathrm{~m}$, lens antenna \\
Antenna gain & $46.21 \mathrm{~dB}$ \\
Beamwidth & $0.68^{\circ}$ \\
Peak power & $1.6 \mathrm{~kW}$ \\
Pulse width & $0.256-1.024 \mu \mathrm{s}$ \\
PRF & $10 \mathrm{kHz}$ \\
System noise power & $-104 \mathrm{dBm}$ \\
Noise figure & $9.4 \mathrm{~dB}$ \\
First and second IF & $156.25 \mathrm{and} 1406.25 \mathrm{MHz}$ \\
Sensitivity $(0 \mathrm{~dB} \mathrm{SNR}$, & $-34.6 \mathrm{dBZ}$ at $1 \mathrm{~km}$ \\
single pulse pair, $0.512 \mu \mathrm{s}$ & \\
pulse width) & \\
Sensitivity $(0.1 \mathrm{~s}$ & $-43.3 \mathrm{dBZ}$ at $1 \mathrm{~km}$ \\
averaging, 0.512 $\mu \mathrm{s}$ & \\
pulse width) & \\
Minimum linear & $-27 \mathrm{~dB}$ \\
depolarization ratio & \\
Unambiguous velocity & $\pm 7.75 \mathrm{~m} \mathrm{~s}-1$ \\
Along-track resolution & $20 \mathrm{~m}$ at $250 \mathrm{~m}$ range \\
& $200 \mathrm{~m}$ at $15 \mathrm{~km}$ range \\
\hline
\end{tabular}

reference unit mounted in the nose cone, just $12^{\prime \prime}$ forward of the reflector, provides the necessary spatial reference and minimizes the moment arm. A consequence of using a reflector plate is that the polarization of the transmitted waveform changes as the reflector plate rotates. A rotational transformation will be used to recover the intrinsic polarization state of the received signal (Vivekanandan et al., 1990).

\subsection{Data system}

HCR places some unique requirements on data system characteristics such as size, weight and environmental factors. Radar control, preliminary signal processing and data display and archiving are handled by a computer located on a $19^{\prime \prime}$ rack mounted in the aircraft cabin, while radar timing, real-time data acquisition and housekeeping are handled by a data system located in the pod. The housekeeping structure consists of system status, GPS time, antenna angle, and aircraft attitude. The cabin and pod data systems are linked by a fiber optic, gigabit network connection. These connections relay radar control commands from the cabin as well as digital time series data, housekeeping and status from the pod.

The received signal is digitized at the rate of $125 \mathrm{MHz}$. Both in-phase and quadrature data are archived in HCR. Standard moment products such as reflectivity, Doppler velocity and spectrum width are provided in CfRadial format (URL: https://www.eol.ucar.edu/content/ standard-data-formats). The moment products are processed and displayed in real time on the archiving computer in the cabin. Data rates for the phase A system are $\sim 70 \mathrm{MB} \mathrm{s}^{-1}$.

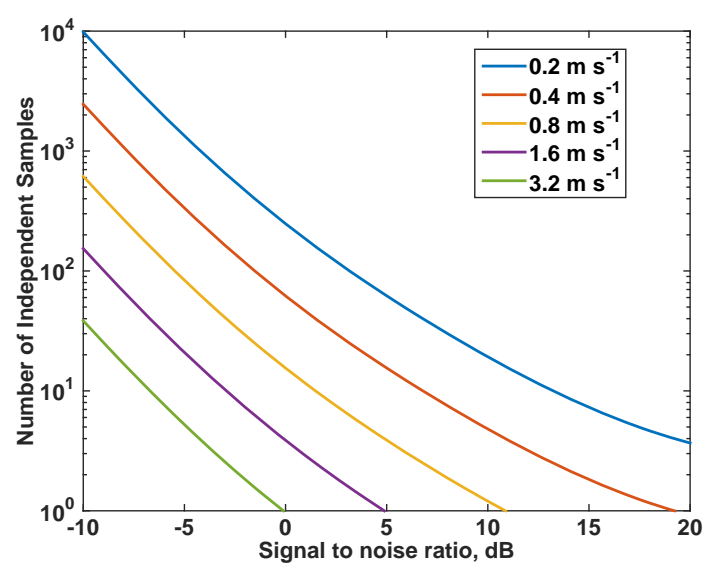

Figure 5. Velocity accuracy as a function of independent samples and signal-to-noise ratio. Spectrum width is assumed $1 \mathrm{~m} \mathrm{~s}^{-1}$, PRF is $10 \mathrm{kHz}$ and transmit frequency is $\mathrm{W}$ band.

This is handled by a single gigabit Ethernet connection coupled to a 24 terabyte redundant array of disks (RAID). Data are simultaneously written to the RAID and two removable external USB3 drives. The USB3 drives offer quick access to data after completion of the research flight.

All HCR data are archived on the NCAR High Performance Storage System (HPSS), a state-of-the-art data center storage facility. Data are available in a CfRadial format and EOL provides basic tools to access those data. EOL supports basic software for display of radar data, editing of radar fields, and derivation of several value-added products.

\section{Performance characteristics of the HCR}

An overview of the performance characteristics achieved by the design of HCR described in Sect. 3 is presented here. For ease of reference some of the important system parameters and performance characteristics under typical operations for HCR are listed in Table 1.

\subsection{Measurement accuracy of mean velocity and reflectivity}

The measurement accuracy of Doppler radial velocity and reflectivity is a function of time-to-independence $\left(T_{\mathrm{D}}\right), \mathrm{PRF}$, and signal-to-noise ratio (SNR) (Doviak and Zrnic, 1993). Time-to-independence determines the interval between two radar measurements that are statistically independent. It is a function of transmit frequency and spectrum width (Bringi and Chandrasekar, 2001). In the case of $\mathrm{W}$ band, $T_{\mathrm{D}}$ is smaller than the corresponding value of $\mathrm{cm}$ wavelength radars. As a result, more independent samples are collected at $\mathrm{W}$ band for a specified dwell time and Doppler spectrum width as compared to larger wavelengths such as S, C, and X bands. 


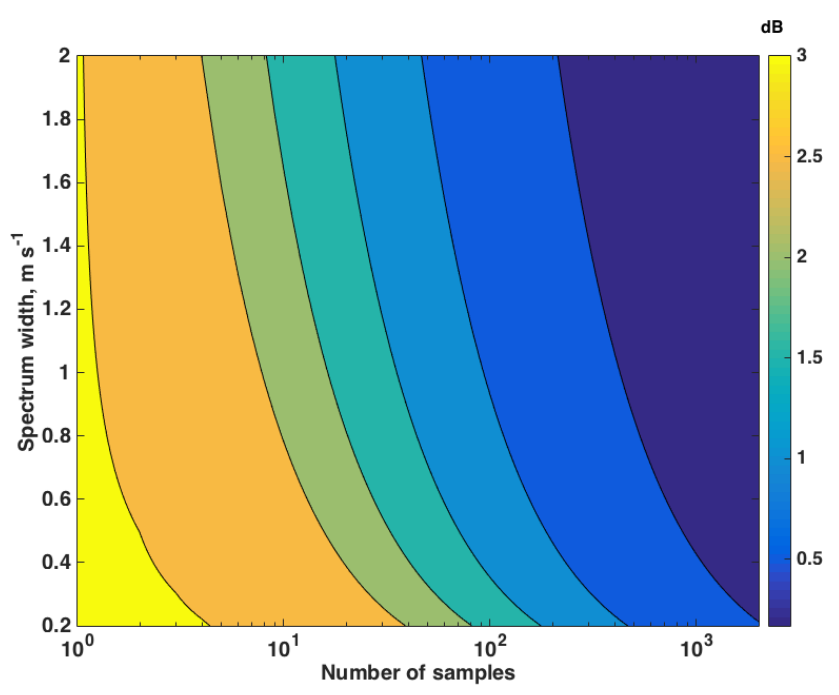

Figure 6. Standard error in reflectivity measurements. For a specified number of samples, standard error in reflectivity becomes lower as the Doppler spectrum becomes broader. For greater than 1000 samples, standard error in reflectivity is $>0.5 \mathrm{~dB}$.

Figure 5 shows the number of independent samples required as a function of signal-to-noise ratio (SNR) for various accuracy values of measured mean radial velocity at $\mathrm{W}$ band. For 100 independent samples, an SNR of $3.5 \mathrm{~dB}$ is required for estimating radial velocity within $0.2 \mathrm{~m} \mathrm{~s}^{-1}$ accuracy. Since $T_{\mathrm{D}}$ at $\mathrm{W}$ band is smaller than at $\mathrm{cm}$ band, more accurate estimates of mean velocity can be achieved in a shorter dwell time interval. Therefore, the HCR offers finer spatial resolution and more accurate radial velocity than a $\mathrm{cm}$ wavelength band airborne radar.

The standard error in HCR reflectivity as a function of Doppler spectrum width and number of samples is shown in Fig. 6 (Bringi and Chandrasekar, 2001). Since the number of independent samples increase as spectrum width increases, standard error reduces for a specified number of samples at higher spectral widths. As the PRF of HCR is $10 \mathrm{kHz}$, averaging 1000 samples or a $0.1 \mathrm{~s}$ time average reduces the standard error of reflectivity to less than $0.5 \mathrm{~dB}$.

\subsection{Sensitivity and spatial resolution}

For the technical specifications listed in Table 1, Fig. 7 shows the sensitivity of the HCR as a function of range for a single pulse-pair measurement. The curves shown in the figure take into account radome attenuation and receiver filter loss. The sensitivity of the HCR can be enhanced by increasing the transmit pulse width and by performing noise subtraction and temporal averaging of the received sample power. Since the transmit pulse width can be varied between 0.256 and $1.024 \mu \mathrm{s}$, the sensitivity of the radar can be enhanced by a transmitting a longer pulse at the expense of range resolution. Reducing the range resolution by increasing the pulse

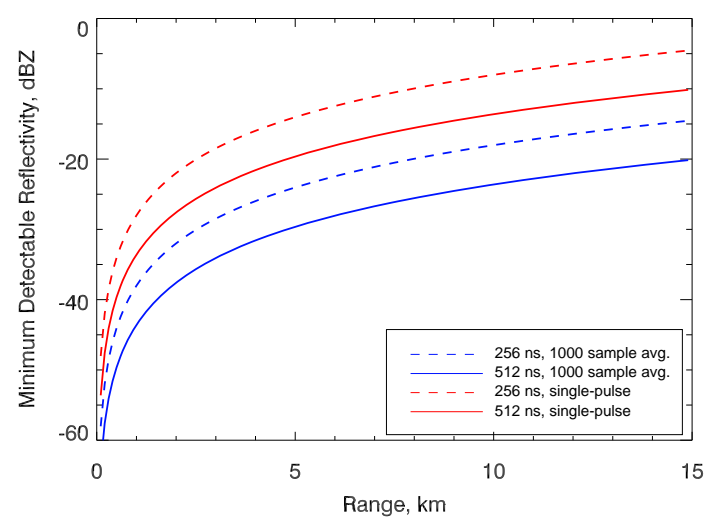

Figure 7. Sensitivity of the HCR as a function of range is shown for two different transmit pulse widths and also for single pulse and averaging over 1000 samples.

length by a factor of 2 improves sensitivity by $6 \mathrm{~dB}$ as shown in Fig. 7. For a Doppler spectrum width of $0.2 \mathrm{~m} \mathrm{~s}^{-1}, T_{\mathrm{D}}$ is $0.0018 \mathrm{~s}$ and averaging over $0.1 \mathrm{~s}$ corresponds to 55 independent samples. Averaging over $0.1 \mathrm{~s}$ and noise subtraction improves the minimum reflectivity by $8.7 \mathrm{~dB}$. In summary, HCR sensitivity is $-37.3 \mathrm{dBZ}$ at $1 \mathrm{~km}$ for a $0.256 \mu$ s transmit pulse width when the received signal is corrected for noise and is averaged over $0.1 \mathrm{~s}$.

Pulse-pair estimates are averaged over a time interval to reduce fluctuations in the Doppler moment estimates, namely, reflectivity, mean velocity and spectrum width. The alongtrack resolution is a function of aircraft speed and the dwell time of the beam. The footprint of the HCR beam is $3 \mathrm{~m}$ at the range of $250 \mathrm{~m}$ and it increases to $180 \mathrm{~m}$ at $15 \mathrm{~km}$ range. Since the aircraft traverses $20 \mathrm{~m}$ during $0.1 \mathrm{~s}$ or $1000 \mathrm{sam}-$ ple averaging, the footprint of the HCR beam increases from 20 to $200 \mathrm{~m}$ as the range increases from $250 \mathrm{~m}$ to $15 \mathrm{~km}$.

Since the PRF is $10 \mathrm{kHz}$, around 100 statistically independent samples can be obtained from clouds with Doppler spectrum width $>0.4 \mathrm{~m} \mathrm{~s}^{-1}$. It should be noted that the number of independent samples is determined by the dwell time of the beam, which is primarily determined by aircraft speed and the Doppler spectrum width of the cloud.

\section{Data quality assurance}

\subsection{Radar system calibration}

Obtaining an accurate system calibration is essential for HCR's scientific missions. Calibration schemes are broadly divided into two categories: internal calibration and external calibration. Internal calibration methods include measurements using a noise source, the calibrated test signal source. External calibration methods include measurements of a corner reflector cross section, backscatter measurements from light precipitation and reflection from the ocean surface. 

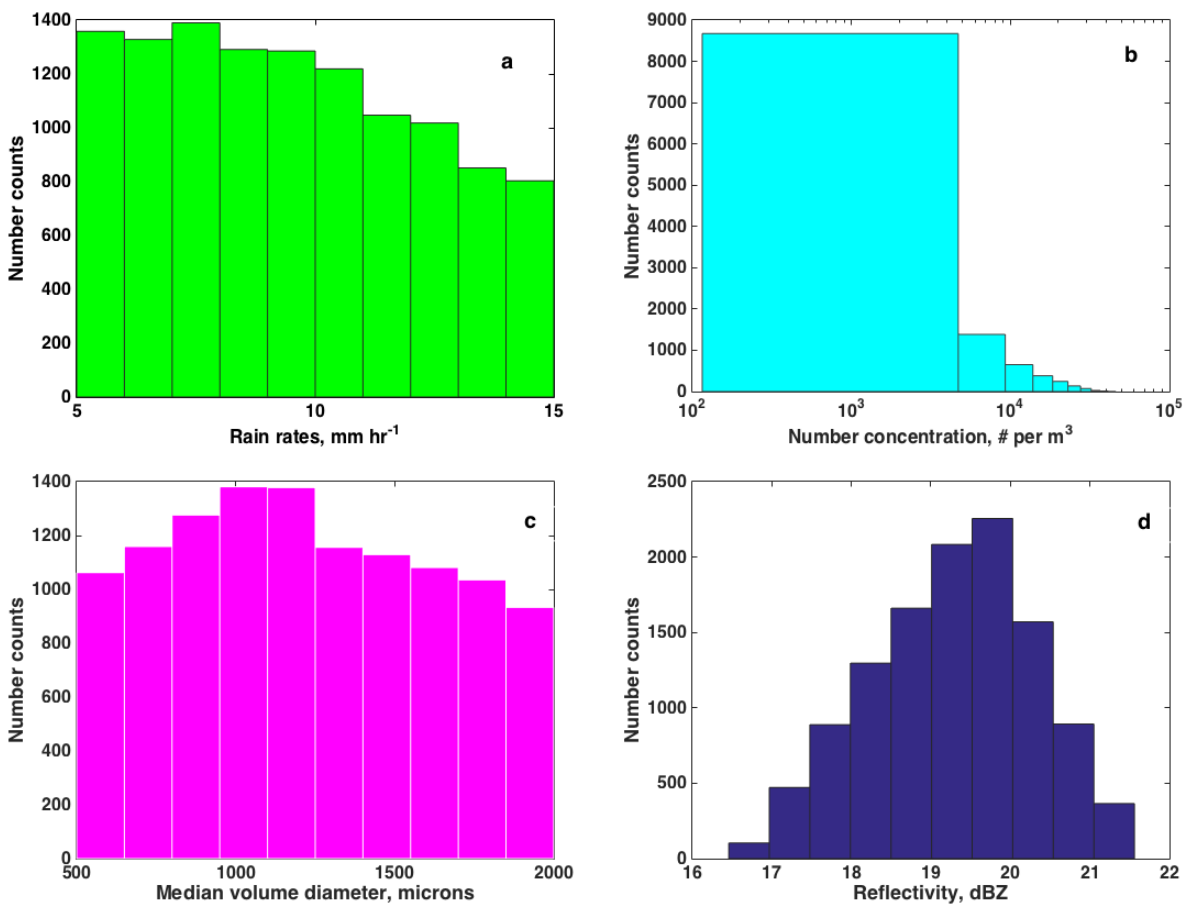

Figure 8. Histograms of rain rates, raindrop size distributions and computed W-band reflectivities: (a) rain rate, (b) concentration, (c) median volume diameter, and (d) reflectivity. Mean value of reflectivity is $19 \mathrm{dBZ}$ and standard deviation is less than dB for rain rates between 5 and $15 \mathrm{~mm} \mathrm{~h}^{-1}$.

\subsubsection{Internal calibration}

Figure 3 shows two internal calibration paths of HCR. The transmit signal is coupled from its path and monitored on a pulse-by-pulse basis by a W-band detector (path colored blue). A known noise source is injected into the receiver path to monitor receiver gain (path colored red). The noise source is switched on to track differential changes in the receiver gain during operation as the receiver gain fluctuates with ambient temperature. The advantage of noise source is its stable performance of better than $0.004 \mathrm{~dB}$ as the ambient temperature varies over $30^{\circ}$. The stable noise source reference allows robust monitoring of the receiver calibration. Due to the limited space in the pressure vessel, the noise source calibration method is configured only for the vertical polarimetric channel. The gain of the horizontal polarimetric channel can be estimated from the physical temperature of the low noise amplifier in conjunction with the known gain of the calibrated vertical polarimetric channel.

\subsubsection{External calibration using measurements from light rain}

Since the reflectivity remains similar for a wide range of rain rates, observations from light rain can be used for verifying the W-band reflectivity (Hogan et al., 2003). At W band, attenuation and Mie scattering dominate scattering from particle sizes $>0.3 \mathrm{~mm}$. The combination of Mie scattering and attenuation effects causes W-band reflectivity measurements at near ranges to saturate (Hogan et al., 2003). Electromagnetic scattering and wave propagation models can be used for quantifying reflectivities of light rain (Vivekanandan et al., 1991). The computation of reflectivity requires the specification of raindrop size distribution parameters. Raindrop size distribution parameters are varied over their natural variations (Ulbrich, 1983). Figure 8a-c show histograms of computed rain rate, median volume diameters and number concentration parameters for rain rates between 5 and $20 \mathrm{~mm} \mathrm{~h}^{-1}$. For these parameters of raindrop size distributions, reflectivity values were calculated using scattering amplitudes (Vivekanandan et al., 1991). Particle shapes were assumed spherical since differential reflectivity for rain at $\mathrm{W}$ band is less than $0.5 \mathrm{~dB}$. The modeled reflectivity values at $200 \mathrm{~m}$ distance from the radar are shown in Fig. 8d. The mean value of the modeled reflectivity is $19.0 \mathrm{dBZ}$ and standard deviation is $0.5 \mathrm{~dB}$.

The calibration procedure using the measurements from light rain is presented only for a ground-based configuration of the HCR. Its radome is protected from rain and condensation by a canopy shelter. The HCR transmitted $256 \mathrm{~ns}$ pulse width and the receiver oversampled the signal for obtaining $19.2 \mathrm{~m}$ range resolution. The far range for the HCR is $57 \mathrm{~m}$. The HCR collects data in the $75 \mathrm{~m}$ range onwards.

Figure $9 \mathrm{a}-\mathrm{c}$ shows ground-based HCR reflectivity, radial velocity and linear depolarization measurements in rain rates 

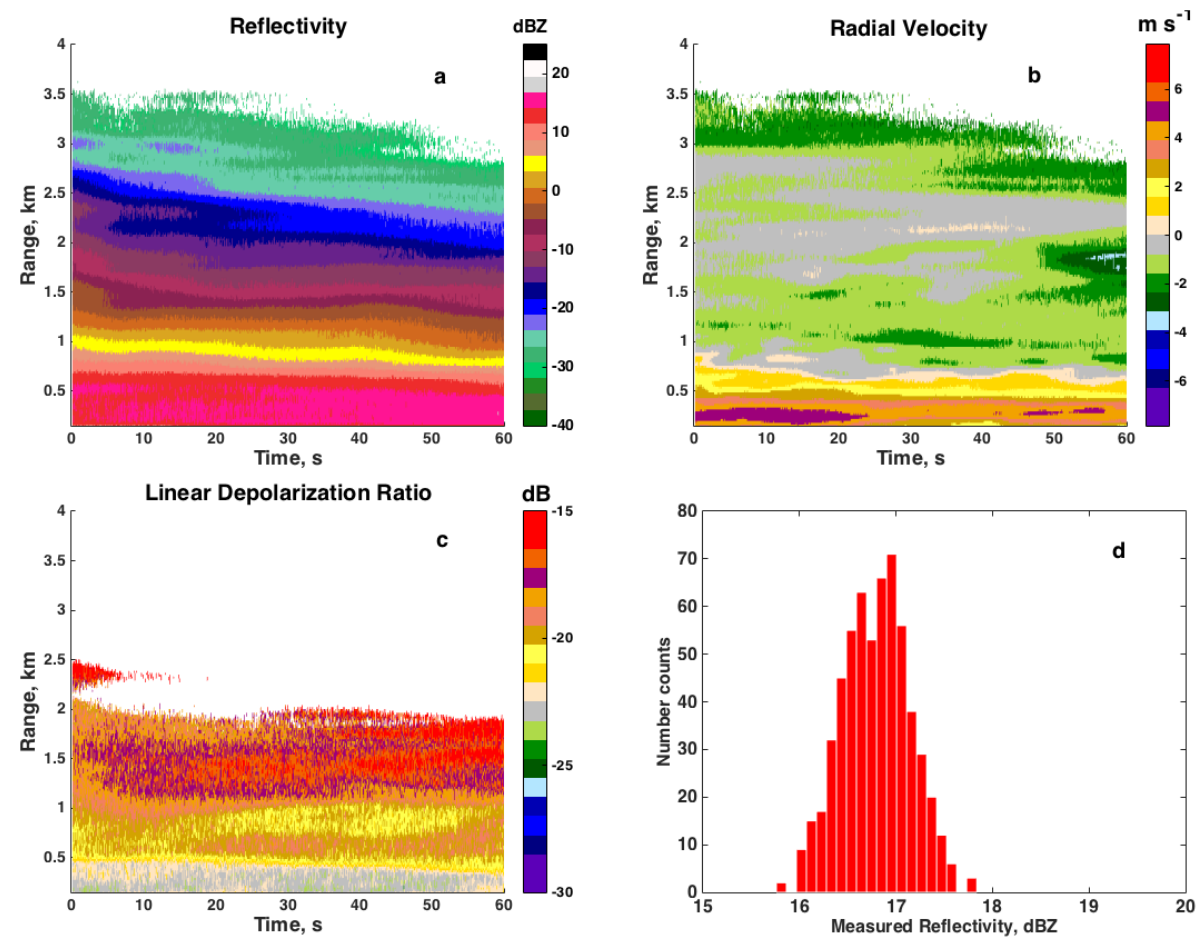

Figure 9. Radar measurements in stratiform rain. The HCR was on the ground and the beam was pointing at $30^{\circ}$ elevation. The B-scan display shows time versus range for the following: (a) reflectivity, (b) velocity and (c) LDR. A histogram of reflectivity at $200 \mathrm{~m}$ is shown in (d).

between 5 and $10 \mathrm{~mm} \mathrm{~h}^{-1}$ for fixed beam pointing as a function of time. The measurements were taken on 8 September 2014 around 21:40 UTC. The radar beam was fixed at $30^{\circ}$ elevation from the horizontal. The reflectivity structure shows frozen precipitation at the top layer, aggregation in the mid-layer and light rain below $400 \mathrm{~m}$ a.g.l. Increased radial velocity and a strong gradient in LDR structure shows the melting level is around $0.5 \mathrm{~km}$ a.g.l. A canopy was used for keeping the radome dry during the rain event. A wet radome attenuates radar signals and will introduce a large uncertainty in reflectivity measurements (Hogan et al., 2003).

A histogram of reflectivity at the $250 \mathrm{~m}$ range is shown in Fig. 9d. The mean value of measured reflectivity is $17.5 \mathrm{dBZ}$. This value is $1.5 \mathrm{~dB}$ lower than the expected value shown in Fig. 8d. Comparison between measured and modeled reflectivity values indicates the measured HCR reflectivity should be increased by $1.5 \mathrm{~dB}$. This result will be verified independently using measurements from a corner reflector and water surface in the future.

\subsection{Correction for platform motion}

In order to obtain sufficient precision and accuracy of Doppler velocity measurements for the types of studies for which the HCR is designed, it is necessary to correct for the platform motion (Lee et al., 1994; Testud et al., 1995; Durden et al., 1999; Bosart et al., 2002; Haimov and Rodi, 2013). Global Position Satellite/Inertial Navigation System (GPS/INS) measurements in the HCR pod are made in order to facilitate correction for the platform motion. The strategy for the HCR is 2-fold. First, during flight the pointing angle of the reflector (i.e., radar beam) is actively corrected for changes in the pod attitude using the real-time navigation data. There is a small time lag in the real-time pointing angle correction, which may result in small errors in the reflector pointing angle. Second, the final data set is generated with the aircraft motion corrected in post-analysis removing any time lag between the navigation data and the radar data. This section describes the navigation data, the real-time pointing angle correction of the reflector and the final aircraft attitude correction procedure.

\subsubsection{Navigation measurements}

The C-MIGITS III GPS/INS system, manufactured by Systron Donner Inertial, is used for platform attitude and motion measurements. The dimensions are approximately $81 \times 90 \times 145.5 \mathrm{~mm}$, the weight is $1.1 \mathrm{~kg}$ and the data rate is $100 \mathrm{~Hz}$. Its compact size makes the C-MIGITS III a good choice because it fits easily in the HCR pod. One advantage of having the GPS/INS system in the pod over using the aircraft system is that the moment arm between the GPS/INS measurement and the reflector is small, significantly simplifying the navigation correction computations. Another ad- 
vantage is that the C-MIGITS III directly measures the motion of the pod including wing and pod flexing that are not measured by the aircraft navigation system. Using navigation measurements from the fuselage would result in the independent motions from wing and pod flexing being unknown and uncorrectable errors in Doppler velocity.

\subsubsection{Real-time pointing stabilization}

When the HCR beam is in staring mode, the reflector can be adaptively corrected for platform motion in real time using the C-MIGITS III output. This physical stabilization of the beam is important when staring at nadir or zenith to minimize the errors from unknown horizontal winds at heights different than the flight level. As an example of these errors, imagine the HCR beam was in nadir pointing mode in order to make measurements in the vertical, but due to platform motion was off by $2^{\circ}$ from the vertical. If at some range the beam encounters a horizontal wind of $30 \mathrm{~m} \mathrm{~s}^{-1}$, the projection of this wind velocity into the beam will be up to about $1 \mathrm{~m} \mathrm{~s}^{-1}$, a large error in vertical radial velocity measurements. Since this wind is typically unknown, these errors cannot be corrected reliably.

The reflector can be corrected fore and aft up to $6^{\circ}$ in each direction. Since the reflector can scan in the cross-track direction, the pointing correction is adequate except in steep banking turns. The reflector pointing position is updated at a rate of $20 \mathrm{~Hz}$. This means that there is a $0.05 \mathrm{~s}$ latency in the reflector position correction in real time. Furthermore, there may be a small offset between the requested pointing angle and what is actually achieved. This offset is typically less than $0.1^{\circ}$. Therefore, final correction of the platform motion must be performed using the navigation data and the measured position of the HCR reflector.

\subsubsection{Final navigation correction}

Many investigators have developed methods to correct airborne Doppler radar velocity measurements for platform motion. This requires both accurate platform motion measurements and accurate beam pointing (Heymsfield, 1989). Lee et al. (1994) derived a comprehensive radar coordinate transformation and expression for measured Doppler velocity including components from platform motion and particle motion (wind plus fall speed). The formulation of Lee et al. (1994) was general enough to be used on different radar platforms and it assumed accurate pointing angles. Haimov and Rodi (2013) propose a set of flight maneuvers to use for calibrating the pointing angle measurements. They show that the pointing angle calibration is consistent for a deployment such that the procedure does not need to be repeated for each flight, only after each radar installation on the aircraft. Once the pointing angle is calibrated, the measured Doppler velocity can easily be corrected with geometric calculations.

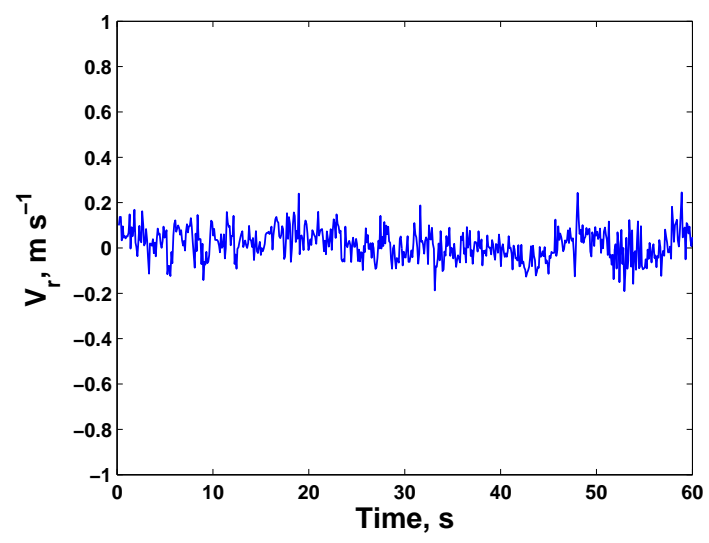

Figure 10. One minute of corrected $V_{\mathrm{r}}$ data within ground echo measured during the test flight of 3 October 2014.

For the HCR, the approach of Haimov and Rodi (2013) is first utilized for calibrating the HCR pointing angle and then the platform motion correction is accomplished as defined in Lee et al. (1994) using the Earth relative coordinates (their Eq. 15).

After correcting for the platform motion, the ground echoes should have a radial velocity of $0 \mathrm{~m} \mathrm{~s}^{-1}$, so the residual $V_{\mathrm{r}}$ represents the errors due to pointing angle offsets combined with errors in vertical motion of the platform measured by the C-MIGITS III and the measurement variance of $V_{\mathrm{r}}$.

The pointing angle calibration and platform motion correction procedure were tested during the fall of 2013. The calibration flight legs to determine the pointing calibration were flown on 17 September 2013 and the correction to the pointing angle applied for the entire project. The measured $V_{\mathrm{r}}$ of ground echoes on subsequent days was analyzed. For example, at nadir pointing the mean and standard deviation of the corrected $V_{\mathrm{r}}$ in ground echo over a $10 \mathrm{~min}$ period on 3 October were found to be 0.001 and $0.086 \mathrm{~m} \mathrm{~s}^{-1}$, respectively. An example of 1 min of corrected $V_{\mathrm{r}}$ within the ground echo is shown in Fig. 10.

Even though the nominal data rate for the HCR data is $10 \mathrm{~Hz}$, the $100 \mathrm{~Hz}$ navigation data are used to correct for platform motion. This is to resolve and correct as much highfrequency platform motion due to turbulence as possible. Thus, the HCR moments are computed at $100 \mathrm{~Hz}$ using the full resolution navigation data, and then the data are averaged to the more practical $10 \mathrm{~Hz}$ nominal time resolution, or any other user-specified temporal resolution. Since HCR nominally runs with a pulse repetition frequency of $10000 \mathrm{~Hz}$, there are 100 samples to compute the moments at $100 \mathrm{~Hz}$, which is sufficient for platform motion correction. This strategy reduces the radial errors in SW and $V_{\mathrm{r}}$ that occur if the platform accelerates at a timescale shorter than the resolution of the navigation data. 


\section{Measurement examples}

The radar is capable of estimating winds and microphysics to a range of $15 \mathrm{~km}$ range with $19.2 \mathrm{~m}$ gate spacing. The HCR can be operated in scanning and staring modes for detecting cloud boundaries, cloud liquid and ice and also for estimating radial winds. Along-track resolution is nominally about $60 \mathrm{~m}$. There is a real-time, onboard display of the HCR measurements. Its capability to serve as a surveillance radar is very limited, as attenuation, and Mie scattering at the $\mathrm{W}$ band frequency would limit maximum detectable reflectivity to about $30 \mathrm{dBZ}$. The dynamic range of HCR reflectivity is between -40 and $30 \mathrm{dBZ}$. Reflectivity can be estimated within $\pm 0.5 \mathrm{~dB}$ accuracy. In weakly and non-precipitating conditions, ice and liquid water content amounts can be estimated from reflectivity measurements.

The HCR will participate in its first field deployment in the summer of 2015. The project is named CSET (Cloud System Evolution in the Trades) and aims to study the characteristics and evolution of stratocumulus clouds over the eastern Pacific Ocean. In preparation for the inaugural HCR project, data have been collected during two test flight campaigns as well as in the ground-based configuration. The motivation for the data collection was primarily engineering tests of calibration, reliability, and platform motion correction. Also being developed are real-time displays onboard the aircraft and analysis tools for post-processing display of the HCR moment and Doppler spectral data. During research flights the HCR operator will be able to monitor system performance and real-time data display. Summary images will be automatically generated at user-specified time intervals and can be sent to a land-based operations center via the GV communications system. Therefore scientists on the ground and in the aircraft can coordinate (via internet chat) during the mission.

Even though there was no particular phenomenon being studied during HCR testing, several interesting data sets have been collected in different weather conditions. These data illustrate the capability and measurement potential of the HCR. Examples of these data sets are shown in this section.

\subsection{Airborne data}

\subsubsection{Winter precipitation with convective features}

Figure 11 shows B-scan plots of $Z e$ and $V_{\mathrm{r}}$ (corrected for platform motion) collected by HCR on the GV looking nadir on 23 February 2013 at 02:11 UTC during an upslope snow event along the Front Range of Colorado. Shown is $1 \mathrm{~min}$ of data, and the vertical axis indicates altitude above mean sea level (a.m.s.l.) and the horizontal axis shows the horizontal distance the GV flew during the minute. The ground echo can be seen as the high reflectivity (black) with $0 \mathrm{~m} \mathrm{~s}^{-1} V_{\mathrm{r}}$ at about $1.7 \mathrm{~km}$ a.m.s.l. As per the standard convention, receding wind from radar has positive sign and approaching
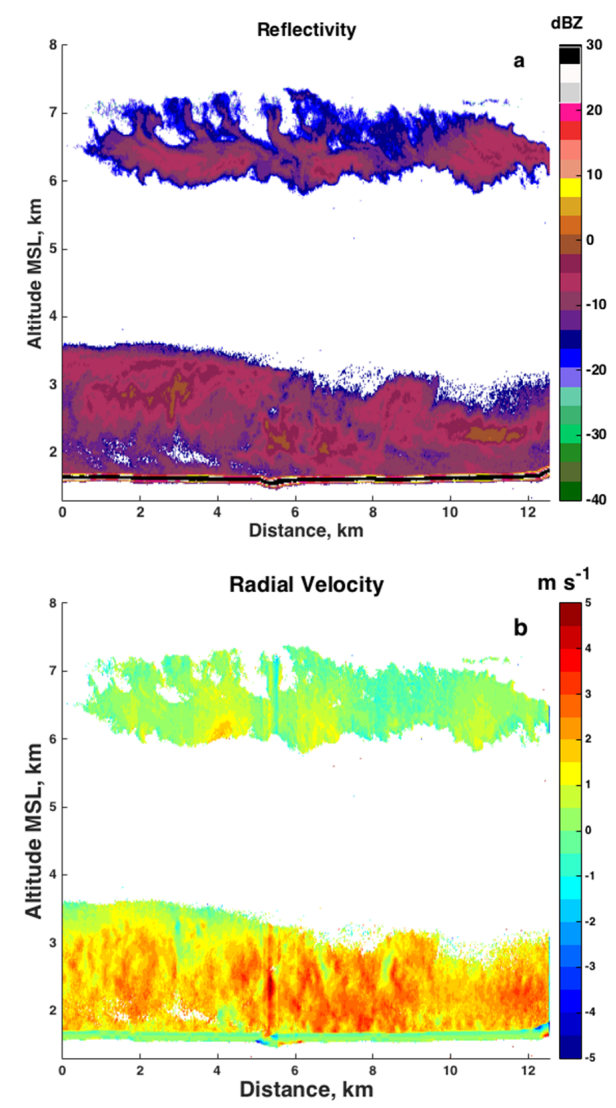

Figure 11. B-scan plots of $Z e$ and $V_{\mathrm{r}}$ collected on 23 February 2013 from the HCR looking nadir.

wind toward radar has negative sign. The 00:00 UTC Denver sounding from the National Weather Service (not shown) indicated the surface temperature was only slightly above $0{ }^{\circ} \mathrm{C}$ and decreased rapidly with height to about $-35^{\circ} \mathrm{C}$ at $7 \mathrm{~km}$ a.m.s.l. Two distinct cloud layers were detected by HCR at this time. Small-scale $(<1 \mathrm{~km})$ convective features are seen at the top of the echo layer between roughly 6 and $7 \mathrm{~km}$ a.m.s.l. The wind at this level was northwesterly at about $25 \mathrm{kts}$ according to the sounding and the plane was flying towards the southwest. The base of the cloud undulates up and down along the horizontal at a scale that is larger than the convective features on top. This layer shows distinct regions of receding, or downward (positive $V_{\mathrm{r}}$ ) and approaching, or upward (negative $V_{\mathrm{r}}$ ) velocity measurements. The largest positive $V_{\mathrm{r}}$ is over $1 \mathrm{~m} \mathrm{~s}^{-1}$ and the largest negative $V_{\mathrm{r}}$ is about $0.8 \mathrm{~m} \mathrm{~s}^{-1}$. The measured $V_{\mathrm{r}}$ is a combination of the fall speed of the particles and the air motion, so the upward $V_{\mathrm{r}}$ measurements indicate vertical air motion and the pattern of alternating upward and downward motion is indicative of waves. The lower layer shown in Fig. 12 is observed to be about $2 \mathrm{~km}$ thick and is a result of easterly upslope flow evident on the Denver sounding. Many fine-scale features are seen in the $Z e$ and $V_{\mathrm{r}}$ fields in the lower level. 


\subsubsection{Stratiform rain and drizzle}

Figure 12 shows B-scan displays of $Z e, V_{\mathrm{r}}$ (platform motion corrected), and also corrected SW. The data were collected by HCR pointing nadir from the GV on 11 October 2013 at 19:26 UTC. Again, 1 min of data is shown and the horizontal axis designates the distance the aircraft travelled in that time. The weather is a stratiform rain and drizzle case. The echo in the low levels is about $3 \mathrm{~km}$ thick. The melting layer is apparent at just below $2 \mathrm{~km}$ a.m.s.l. and is indicted by an increase in the $Z e, V_{\mathrm{r}}$ and $\mathrm{SW}$. The increase in $Z e$ is due to the increase in the refractive index of liquid over snow and ice crystals. As the ice melts the density increases and thus so does the fall speed, resulting in the increase in $V_{\mathrm{r}}$. The increase in SW below the melting layer is due, at least partially, to the fact that liquid drops exhibit a larger range of fall speeds and larger differences in terminal fall speed for different sizes. Additional turbulence in the boundary layer will also contribute to the increase in measured SW. There is also a small cirrus cloud at about $9 \mathrm{~km} \mathrm{~m}$.s.l. detected with measured $\mathrm{Ze}$ values between about -30 and $-39 \mathrm{dBZ}$. Interestingly the measured $V_{\mathrm{r}}$ varies in the cirrus from roughly $0 \mathrm{~m} \mathrm{~s}^{-1}$ to almost $1 \mathrm{~m} \mathrm{~s}^{-1}$.

\subsection{Ground-based data}

The HCR was also deployed in its ground-based configuration with coincident high spectral resolution lidar (HSRL) (Eloranta, 2005) data looking vertically in November of 2013 in Boulder Colorado. Figure 13 shows B-scan displays of HCR $Z e$ and $V_{\mathrm{r}}$ on 22 November 2013 from 04:00 to 05:00 UTC during a snow event. Light snow was falling at the surface and the Denver sounding (not shown) indicated the temperature was below freezing for the entire layer and the surface temperature was about $-10^{\circ} \mathrm{C}$. The $Z e$ values are low and do not exceed about $-10 \mathrm{dBZ}$, consistent with the light snow observed at the surface. The $V_{\mathrm{r}}$ values are all negative (approaching), consistent with the downward motion of ice crystals falling.

The HSRL data in Fig. 13 shows a layer of high backscatter and low circular depolarization, indicating there is a layer containing super-cooled liquid drops at the top of the observed cloud. Using the HSRL data alone it is difficult to determine if the layer containing super-cooled liquid is mixed phase or not - i.e., does the layer also contain ice crystals. Since the liquid cloud droplets dominate the lidar measurements, the backscatter signal from any ice crystals is masked in this layer. The apparent fall streaks that can be seen coming from the bottom of the liquid layer are consistent with the presence of ice crystals falling out of the liquid layer (Shupe et al., 2008). Examining the HCR $V_{\mathrm{r}}$ data in Fig. 14b, it can be seen that the $V_{\mathrm{r}}$ values in the HSRL-indicated liquid layer are negative, ranging from -0.5 to $-1.0 \mathrm{~m} \mathrm{~s}^{-1}$. This is also consistent with the presence of ice crystals falling out of the layer, assuming the vertical air velocity is close to $0 \mathrm{~m} \mathrm{~s}^{-1}$.
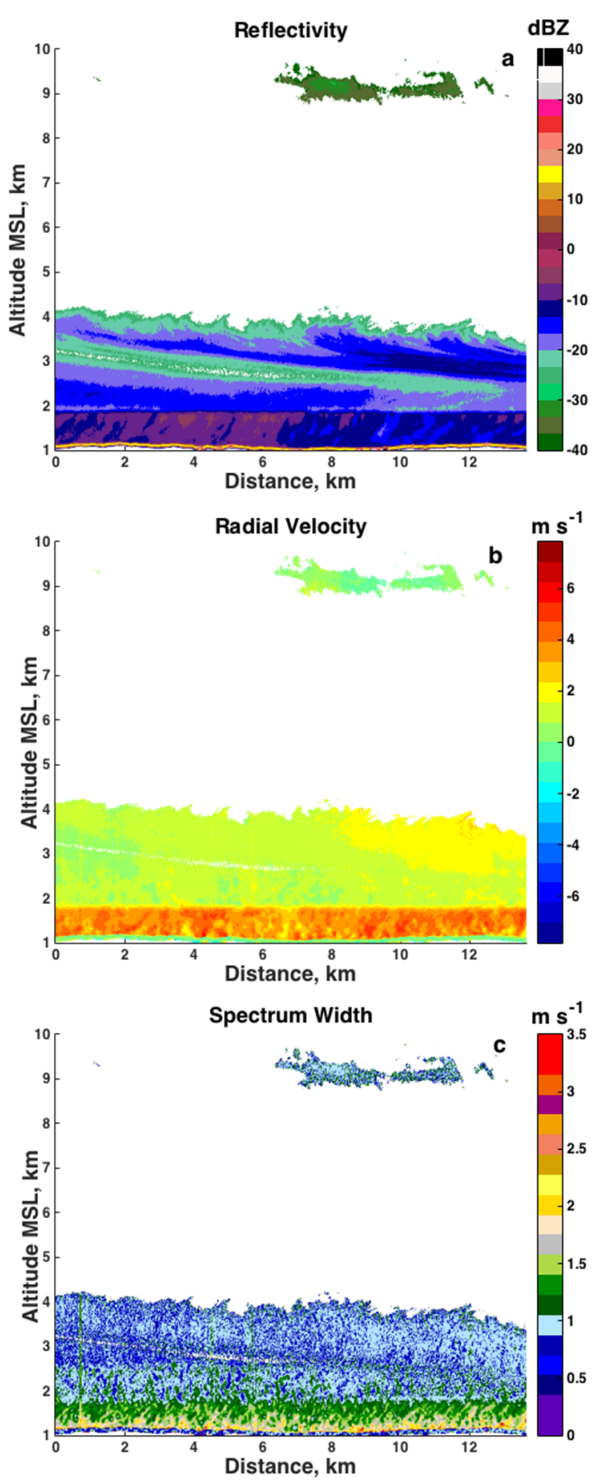

Figure 12. B-scan plots of $Z e, V_{\mathrm{r}}$ and spectrum width collected on 11 October 2013 from the HCR looking nadir.

The definitive evidence is the HCR spectral data presented in Fig. 14, which shows the received power as a function of $V_{\mathrm{r}}$ within a given range gate. The spectra are obtained by taking the fast Fourier transform of the time-series in-phase and quadrature $(I$ and $Q$ ) data to determine the return power (after accounting for the radar constant) as a function of Doppler velocity. The spectrum in Fig. 14 was selected from a radar range gate within the liquid layer that had a measured $V_{\mathrm{r}}$ of about $-0.5 \mathrm{~m} \mathrm{~s}^{-1}$. The spectrum is bimodal with a peak close to $0 \mathrm{~m} \mathrm{~s}^{-1}$ and a peak close to $-0.9 \mathrm{~m} \mathrm{~s}^{-1}$. The two peaks indicate two distinct populations of particles with different fall speeds. The peak near $0 \mathrm{~m} \mathrm{~s}^{-1}$ is most likely due to liquid cloud droplets that do not have an appreciable fall speed, while the peak near $-0.9 \mathrm{~m} \mathrm{~s}^{-1}$ is most likely caused 

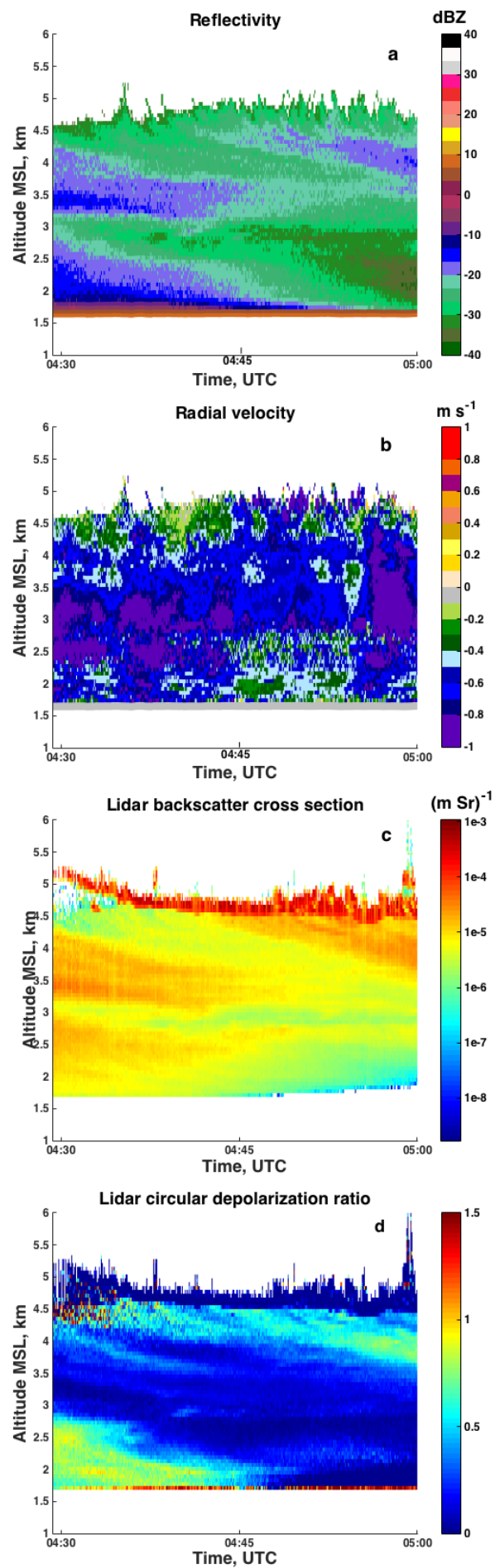

Figure 13. Coincident ground-based HCR and HSRL measurements of liquid and ice clouds. (a) W-band reflectivity, (b) W-band radial velocity, (c) lidar backscatter and (d) lidar circular depolarization ratio. Data were collected on 22 November 2013.

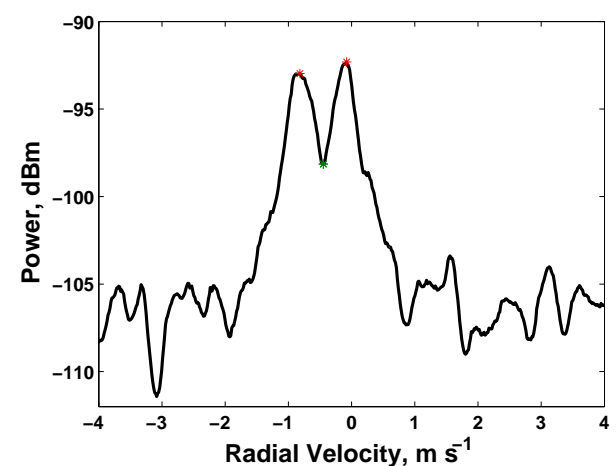

Figure 14. HCR spectrum collected in a mixed-phase cloud. The radar was ground-based and pointed vertically.

by ice crystals that are forming in the liquid layer growing quickly and falling out (Danne et al., 1999). In order to obtain a smooth spectrum from a single gate, the finite impulse response (FIR) filter of Hubbert and Bringi (1995) was used on the original spectrum data. It was found that using the FIR filter was preferable to using time or range averaging because the cloud was moving and evolving quickly.

The HCR and HSRL measurements are often complementary and the combination of the two can provide additional insights into the cloud being studied. In the ground-based configuration, the two instruments can share a single standard $20 \mathrm{ft}$ shipping container for coincident operations. The GV can also deploy the instruments simultaneously.

Ground-based vertically pointing W-band spectral data have been shown to be useful for separating the air velocity from the particle fall velocity (Luke et al., 2010; Luke and Kollias, 2013; Danne et al., 1999). In clouds, bimodal spectra result from the presence of two different size modes, namely, small cloud drops on the order of several microns and larger precipitating particles of either ice or liquid drizzle. As seen in Fig. 14, the two populations can result in two distinguishable peaks at different $V_{\mathrm{r}}$ values. The cloud droplets are assumed to be moving with the wind and therefore the cloud peak represents the air motion. The distinct spectra can be analyzed independently, thus providing detailed microphysical information that would not be obtainable without the spectral data.

\section{Summary}

The HCR is an airborne, mm wavelength, dual-polarization polarimetric, Doppler radar that serves the atmospheric science community by providing cloud remote sensing capabilities. Engineering and scientific aspects of the pod-based HCR are described in the paper. The pod-based configuration alleviates competition for cabin space onboard the GV (or other) aircraft and offers flexible scan coverage. The challenges associated with a pod-based system on a high-altitude 
platform are managed by housing the radar system in a pressurized vessel within the pod. The compact pod-based configuration minimized waveguide losses and offered expected sensitivity for detecting clouds. Results presented in this paper regarding spatial and temporal resolutions and sampling requirements for desired accuracy in radar measurements can be used for designing an optimal data collection strategy for a specified scientific mission.

The current system is a single-frequency polarimetric Doppler radar. The transmit and receive systems are designed to accommodate implementation of pulse compression to achieve finer range resolution. The layout of the pod will accommodate a second radar at $K_{\mathrm{a}}$ band for dual-wavelength measurements. Inclusion of dual-wavelength capability will significantly enhance the accuracies of retrieved cloud microphysical quantities.
Internal and external calibration schemes are used for monitoring data quality. For radar systems, internal calibration is important to track changes in the receiver gains. The methodology presented in this paper for calibrating reflectivity makes use of light rain as a calibration target and it ensures standard error reflectivity measurements $<0.5 \mathrm{~dB}$. The amount of aircraft motion contribution to airborne Doppler measurements is determined by aircraft velocity along the radar beam pointing direction. This requires precise estimates of the antenna pointing angle and aircraft attitude and velocity. The two-step procedure for correcting the influence of platform motion on measured radial velocity ensures better than $0.1 \mathrm{~m} \mathrm{~s}^{-1}$.

Preliminary measurements show the radar is capable of estimating accurate reflectivity and velocity observations for climate science and cloud process studies that are dominated by cloud liquid and cloud ice particles. The HCR will serve the atmospheric science research community by adding $\mathrm{mm}$ wavelength remote sensing capabilities to the HIAPER aircraft. The HCR measurements in conjunction with other HIAPER instrumentation have the potential to significantly increase our understanding of cloud physics. 


\section{Appendix A}

Table A1. List of acronyms.

\begin{tabular}{|c|c|}
\hline CRS & Cloud Radar System \\
\hline CfRadial & Climate and forecasting radial \\
\hline $\mathrm{dBZ}$ & Radar reflectivity factor \\
\hline EIKA & Extended interaction klystron amplifier \\
\hline EOL & Earth Observing Laboratory \\
\hline FAA & Federal aviation Administration \\
\hline GV & Gulfstream V \\
\hline HCR & HIAPER Cloud Radar \\
\hline HALO & High-altitude long-range research aircraft \\
\hline HPSS & High Performance Storage System \\
\hline HIAPER & High-Performance Instrumented Airborne Platform for Environmental Research \\
\hline HSRL & High Spectral Resolution Lidar \\
\hline ICPR & Integrated cross-polar ratio \\
\hline IF & Intermediate frequency \\
\hline LNA & Low noise amplifier \\
\hline LDR & Linear depolarization ratio \\
\hline m.s.l. & Mean sea level \\
\hline NCAR & National Center for Atmospheric Research \\
\hline NOAA & National Oceanic and Atmospheric Administration \\
\hline NSF & National Science Foundation \\
\hline PRF & Pulse repetition frequency \\
\hline QC & Quality control \\
\hline RAID & Redundant array of inexpensive disks \\
\hline $\mathrm{RF}$ & Radio frequency \\
\hline RHI & Range height indicator \\
\hline $\mathrm{Rx}$ & Receiver \\
\hline SNR & Signal-to-noise ratio \\
\hline Solo & Software for radar translation, visualization, editing and interpolation \\
\hline STSR & Simultaneously transmit and simultaneously receive \\
\hline$T_{\mathrm{D}}$ & Time-to-independence \\
\hline$T x$ & Transmitter \\
\hline $\mathrm{V}$ & Vertical \\
\hline$V_{\mathrm{r}}$ & Radial velocity \\
\hline$Z e$ & Reflectivity \\
\hline$\lambda_{\mathrm{o}}$ & Transmit wavelength \\
\hline
\end{tabular}


Acknowledgements. NCAR is primarily funded by the National Science Foundation. This material is based upon work supported by the National Science Foundation under cooperative grant numbers NSF0015 and MO904552. Any opinions, findings, and conclusions or recommendations expressed in this material are those of the author(s) and do not necessarily reflect the views of the National Science Foundation.

The guidance and support of Al Cooper of NCAR was invaluable throughout the development. The authors would like to thank Mike Strong for his technical expertise and leadership in the project. We also thank James Ranson, David Allen and Karl Schwenz of the NCAR Design and Fabrication Services for fabrication and design of mechanical infrastructure. The authors also thank Sam Haimov of the University of Wyoming for many helpful technical discussions. The authors appreciate Charlie Martin's extensive software development for the initial prototype. The authors appreciate the thoughtful and helpful manuscript review by John Hubbert of NCAR.

Edited by: M. Zribi

\section{References}

Bosart, B. L., Lee, W. C., and Wakimoto, R. M.: Procedures to improve the accuracy of airborne Doppler radar data, J. Atmos. Ocean. Tech., 19, 322-339, 2002.

Bringi, V. N. and Chandrasekar, V.: Polarimetric Doppler Weather Radar, Cambridge University Press, New York, 2001.

Brown, P. R., Illingworth, A. J., Heymsfield, A. J., McFarquhar, G. M., Browning, K. A., and Gosset, M.: The role of spaceborne millimeter-wave radar in the global monitoring of ice clouds, J. Appl. Meteorol., 34, 2346-2366, 1995.

Clothiaux, E. E., Miller, M. A., Albrecht, B. A., Ackerman, T. P., Verlinde, J., Babb, D. M., Peters, R. M., and Syrett, W. J.: An evaluation of a 94-GHz radar for remote sensing of cloud properties, J. Atmos. Ocean. Tech., 12, 201-229, 1995.

Danne, O., Quante, M., Milferstädt, D., Lemke, H., and Raschke, E.: Relationships between Doppler Spectral Moments within Large-Scale Cirro- and Altostratus Cloud Fields Observed by a Ground-Based 95-GHz Cloud Radar, J. Appl. Meteorol., 38, 175-189, doi:10.1175/15200450(1999)038<0175:RBDSMW>2.0.CO;2, 1999.

Donovan, D. P. and van Lammeren, A. C. A. P.: Cloud effective particle size and water content profile retrievals using combined lidar and radar observations 1 . Theory and examples, J. Geophy. Res., 106, 27425-27448, 2001.

Doviak, R. J. and Zrnic, D.: Doppler Radar and Weather Observations, Academic Press, San Diego, CA, 562 pp., 1993.

Durden, S. L., Haddad, Z. S., and Bui, T. P.: Correction of Doppler radar data for aircraft motion using surface mea- surements and recursive least squares estimation, J. Atmos. Ocean. Tech., 16, 2026-2029, 1999.

Ellis, S. M. and Vivekanandan, J.: Water vapor estimates using simultaneous dual-wavelength radar observations, Radio Science, 45, RS5002, doi:10.1029/2009RS004280, 2010.

Ellis, S. M. and Vivekanandan, J.: Liquid water content estimates using simultaneous $S$ and $K_{\mathrm{a}}$-band radar measurements, Radio Science, 46, RS2021, doi:10.1029/2010RS004361, 2011.
Eloranta, E. W.: High Spectral Resolution Lidar in Lidar: RangeResolved Optical Remote Sensing of the Atmosphere, in: Springer Series in Optical Sciences, edited by: Weitkamp, K., Springer-Verlag, New York, 2005.

Haimov, S. and Rodi, A.: Fixed-antenna pointing-angle calibration of airborne Doppler cloud radar, J. Atmos. Ocean. Tech., 30, 2320-2335, doi:10.1175/JTECH-D-12-00262.1, 2013..

Hamazu, K., Hashiguchi, H., Wakayama, T., Matsuda, T., Doviak, R. J., and Fukao, S.: A 35-GHz scanning Doppler radar for fog observations, J. Atmos. Ocean. Tech., 20, 972-986, 2003.

Hanesiak, J., Stewart, R., Barber, D., Liu, G., Gilligan, J., Desjardins, D., Dyck, R., Fargey, S., Hochheim, K., Martin, R., Taylor, P., Biswas, S., Gordon, M., Melzer, M. A., Moore, K., Field, R., Hay, C., Zhang, S., McBean, G., Strapp, W., Hudak, D., Scott, J., Wolde, M., Goodson, R., Hudson, E., Gascon, G., Greene, H., Henson, W., and Laplante, A.: Storm studies in the Arctic, B. Am. Meteorol. Soc., 91, 47-68, 2010.

Heymsfield, G. M.: Accuracy of Vertical Air Motions from NadirViewing Doppler Airborne Radars, J. Atmos. Ocean. Tech., 6, 1079-1082, 1989.

Hogan, R. H., Bouniol, D., Ladd, D. N., O'Connor, E. J., and Illingworth, A. J.: Absolute Calibration of 94/95-GHz Radars Using Rain, J. Atmos. Ocean. Tech., 20, 572-580, 2003.

Horie, H., Iguchi, T., Hanado, H., Kuroiwa, H., Okamoto, H., and Kumagai, H.: Development of a 95-GHz airborne cloud profiling radar (SPIDER) - Technical aspects, IEICE Trans. Comm., E83B, 2010-2020, 2000.

Hubbert, J. and Bringi, V. N.: An iterative filtering technique for the analysis of copolar differential phase and dual-frequency radar measurements, J. Atmos. Ocean. Tech., 12, 643-648, 1995.

Kollias, P. and Albrecht, B. A.: The turbulence structure in a continental stratocumulus cloud from millimeter wavelength radar observation, J. Atmos. Sci., 57, 2417-2434, 2000.

Kollias, P., Albrecht, B. A., Lhermitte, R., and Savtchenko, A.: Radar observations of updrafts, downdrafts, and turbulence in fair-weather cumuli, J. Atmos. Sci., 58, 1750-1766, 2001.

Kollias, P., Albrecht, B. A., and Marks Jr., F.: Why Mie? Accurate observations of vertical air velocities and raindrops using cloud radar. B. Am. Meteorol. Soc., 82, 1471-1483, 2002.

Kollias, P., Clothiaux, E. E., Miller, M. A., Albrecht, B. A., Stephens, G. L., and Ackerman, T. P.: Millimeter-Wavelength Radars: New Frontier in Atmospheric Cloud and Precipitation Research, B. Am. Meteorol. Soc., 88, 1608-1624, doi:10.1175/BAMS-88-10-1608, 2007.

Kropfli, R. A. and Kelly, R. D.: Meteorological research applications of MM-wave radar, Meteorl. Atmos. Phys., 59, 105-121, 1996.

Lee, W.-C., Dodge, P., Marks, F. D., and Hildebrand, P. H.: Mapping of airborne Doppler radar data, J. Atmos. Ocean. Tech., 11, 572-578, 1994.

Laursen, K. K., Jorgensen, D. P., Brasseur, G. P., Ustin, S. L., and Hunning, J.: HIAPER: The next generation NSF/NCAR research aircraft, B. Am. Meteorol. Soc., 87, 896-909, 2006.

Lhermitte, R.: A 94-GHz Doppler radar for cloud observations, J. Atmos. Ocean. Tech., 4, 36-48, 1987.

Li, L., Heymsfield, G. M., Racette, P. E., Tian, L., and Zenker, E.: A 94-GHz cloud radar system on a NASA high-altitude ER-2 aircraft, J. Atmos. Ocean. Tech., 21, 1378-1388, 2004. 
Luke, E. P. and Kollias, P.: Separating Cloud and Drizzle Radar Moments during Precipitation Onset Using Doppler Spectra, J. Atmos. Ocean. Tech., 30, 1656-1671, doi:10.1175/JTECH-D-1100195.1, 2013.

Luke, E. P., Kollias, P., and Shupe, M. D.: Detection of supercooled liquid in mixed-phase clouds using radar Doppler spectra, J. Geophys. Res., 115, D19201, doi:10.1029/2009JD012884, 2010.

Pazmany, A. L., McIntosh, R. E., Kelly, R., and Vali, G.: An airborne $95-\mathrm{GHz}$ dual-polarized radar for cloud studies, IEEE T. Geosci. Remote, 32, 731-739, 1994.

Shupe, M. D., Daniel, J. S., de Boer, G., Eloranta, E. W., Kollias, P., Luke, E., Long, C. N., Turner, D., and Verlinde, J.: A Focus on Mixed-Phase Clouds, B. Am. Meteorol. Soc., 89, 1549-1562, 2008.

Stephens, G. L., Vane, D. G., Boain, R. J., Mace, G. G., Sassen, K., Wang, Z., Illingworth, A. J., O’Connor, E. J., Rossow, W. B., Durden, S. L., Miller, S. D., Austin, R. T., Benedetti, A., Mitrescu, C., and the CloudSat Science Team: The CloudSat mission and the A-train, B. Am. Meteorol. Soc., 83, 1771-1789, 2002.

Testud, J., Hildebrand, P. H., and Lee, W.-C.: A procedure to correct airborne Doppler radar data for navigation errors using the echo returned from the earth's surface, J. Atmos. Ocean. Tech., 12, 800-820, 1995.
Ulbrich, C. W.: Natural variations in the analytical form of the raindrop size distribution, J. Clim. Appl. Meteorol., 22, 1764-1775, 1983.

Valli, G., Kelly, R. D., French, J., Haimov, S., Leon, D., McIntosh, R. E., and Pazmany, A.: Finescale structure and microphysics of coastal stratus, J. Atmos. Sci., 55, 3540-3564, 1998.

Vivekanandan, J., Adams, W. M., and Bringi, V. N.: Rigorous approach to polarimetric radar modeling of hydrometeor orientation distributions, J. Appl. Meteorol., 30, 1053-1063, 1991.

Vivekanandan, J., Turk, J., Stephens, G. L., and Bringi, V. N.: Microwave radiative transfer studies using combined multiparameter radar and radiometer measurements during COHMEX, J. Appl. Meteorol., 29, 561-585, 1990.

Wolde, M. and Vali, G.: Polarimetric signatures from ice crystals observed at $95 \mathrm{GHz}$ in winter clouds, Part I: Dependence on crystal form, J. Atmos. Sci., 58, 828-841, 2001a.

Wolde, M. and Vali, G.: Polarimetric signatures from ice crystals observed at $95 \mathrm{GHz}$ in winter clouds, Part II: Frequency of occurrence, J. Atmos. Sci., 58, 842-849, 2001 b.

WCR: Wyoming Cloud Radar, University of Wyoming, Laramie, available online at: http://www-das.uwyo.edu/wcr/ (last access: 14 August 2015), 2012. 